Article

\title{
How Does Climate Change Affect Rice Yield in China?
}

\author{
Wenjian He ${ }^{1}$, Yiyang Liu ${ }^{1, *}$, Huaping Sun ${ }^{2} \mathbb{D}$ and Farhad Taghizadeh-Hesary $3, * \mathbb{C}$ \\ 1 College of Business, Nanjing University of Information Science \& Technology, Nanjing 210044, China; \\ hewenjian@126.com \\ 2 Institute of Industrial Economics, School of Finance and Economics, Jiangsu University, Zhenjiang 212013, \\ China; shp@ujs.edu.cn \\ 3 Social Science Research Institute, Tokai University, Hiratsuka-shi, Kanagawa-ken 259-1292, Japan \\ * Correspondence: njhxzh@njfu.edu.cn (Y.L.); farhad@tsc.u-tokai.ac.jp (F.T.-H.)
}

Received: 3 August 2020; Accepted: 26 September 2020; Published: 28 September 2020

\begin{abstract}
The global warming phenomenon has undoubtedly brought unprecedented challenges to rice production, vital for food security in Southeast Asian countries and China. Most studies on this topic have focused narrowly on the direct effect of climate change on rice yield, neglecting the indirect effect. Using panel data from 30 provinces in China from 1990 to 2016, in this paper, we propose and test a mediational effect model to examine the mechanisms of how climate change affects rice yield. We find that climate change leads to changes in functional irrigation areas, farmers' fertilizing behavior, and agricultural labor supply, and it is these mediating factors that effectively transmit the impact of climate change to China's rice production. The positive indirect impact of climate change on the factors of production often partially or overly compensates for the adverse direct effect of climate change on rice yield, leading to a surprising observation of the association of climate change with increased rice yield, at least in the short run. We also provide some preliminary policy advice based on the analysis.
\end{abstract}

Keywords: climate change; effective irrigation area; chemical fertilizer application; labor supply; rice yield

\section{Introduction}

The significant impact of global climate change on the natural environment, economy, and society have drawn international attention [1]. The dangers potentially caused by climate change range from natural disasters to broken biological chains, involving almost all aspects of human survival [2]. Agriculture, as a fundamental sector in the economy, is susceptible to climate change [3]. The threat of climate change to world agricultural production cannot be underestimated. According to a special report on Climate Change and Land (SRCCL) published by Intergovernmental Panel on Climate Change (IPCC), about one-third of global food production will be affected by climate change by August 2019. Consequently, climate change has become a significant challenge in addressing global food supplies and future famine aversion.

China, located in East Asia, is one of the countries facing the most significant risk of climate change globally, as indicated by its wide monthly, annual, and inter-annual variations in precipitation and temperature. The peculiarity of its nature and geographical location makes China's agriculture more vulnerable to climate change [4]. With the increase of accumulated temperature and intensification of drought in the south and flood in the north, the weather condition has been non-optimal for rice growth, contributing to the reduction of rice production [5]. Without a doubt, agriculture is an essential sector in China's economy that provides employment for more than 300 million farmers and supports 
over $20 \%$ of the world's population with only $8 \%$ of the global sown area. Moreover, the total cultivated area of rice in China is 31 million ha, accounting for about $20 \%$ worldwide, second only to India.

Meanwhile, rice is a staple food for about 780 million people in China. China's rice yield needs to meet the increasing demand for food in a rapidly expanding economy with the world's largest population. Thus, how climate change affects Chinese rice yield, a question that concerns the welfare of 1.3 billion people's livelihood and that can generate a profound impact on the world food markets, should be paid close attention to [6].

The relationship between climate change and rice yield has been a standard topic. Scholars mainly focus on the impact of temperature and precipitation, two significant factors of climate conditions, on rice yield, and quality [7]. Some scholars use crop models to measure the impact of past and present climate change on regional or nationwide agriculture and to predict future development trends $[8,9]$. For instance, Yang and colleagues [9] use a regional calibrated crop model and found that a $1{ }^{\circ} \mathrm{C}$ rise in temperature decreases rice yield by roughly $4 \%$ in the rice production areas. Meanwhile, an increased level of precipitation also led to decreased rice yield in 16 major rice-producing regions in Bangladesh. However, the regional calibrated crop model focuses on analyzing the crop physiological mechanisms in response to climate change, neglecting the impact of market factors. Hence, the effect of climate change on crops tends to be overestimated $[10,11]$. Therefore, to make up for the shortcomings of crop models, more and more scholars have begun to use an econometric model to explore the relationship between climatic factors and crop yield by controlling market factors and social factors [12,13]. For instance, Schlenker [14] uses a fixed-effect model and finds that temperature changes have a much more substantial impact on African yield than precipitation changes. Moreover, regressions between national rice yield and climate indicate that in most countries, the increased maximum temperature was more harmful to rice than increased minimum temperature [15]. Quantitative analysis of the relationship between climate change and rice yield has been conducted to provide essential data for policymaking to solve food security and environmental sustainability problems.

Existing research on this topic abounds from the aspects of biology and economics. However, most of the existing studies have focused on the direct effect of climate change, short of analyzing the mechanisms through which climate change makes a difference to rice yield. A study of the internal mechanism of how climate change influences rice yield can further open the "black box" of the relationship between them. Our main contribution is to pay close attention to the indirect effects of climate change on rice yield. The study aims to explain the channels through which climate conditions affect rice productivity by identifying the mediational effects of several rice production factors in response to climate change. In particular, we demonstrate that to evaluate the effect of climate change on rice yield, we cannot overlook the reactions of effective irrigation area, fertilizer applications, and agricultural labor force to the changing climate conditions and how those endogenous responses eventually affect rice yield.

Meanwhile, the quantitative analysis in existing research is mostly based on weather variation. The results reflect rice yield to short-run weather shocks rather than long-run climate change [16]. As a result, this paper uses long-average weather as a proxy for the climate change estimation framework to identify climate change effects on rice yield. Our analysis provides a basis for the government to put forward applicable policies to address the growing demand for China's food production and food security.

The rest of the paper is organized as follows: In Section 2, we briefly review the relevant literature and put forward a theoretical hypothesis of the moderating effect of climate change for rice production in the context of the existing literature. Section 3 explains the data used in this paper, the variable selections, and the setup of the empirical model. Section 4 describes the empirical results and offers further discussions on the regression results. Finally, in Section 5 we conclude and offer several preliminary policy recommendations. 


\section{Literature Review and Theoretical Hypotheses}

\subsection{Direct Effect of Climate Change on Rice Yield}

The excessive-high temperature will increase the risk of heat stress, which will not only make anthers challenging to crack, contributing to the reduction of pollen, thus affecting the normal process of pollination and fertilization. Meanwhile, excessive heat will inhibit rice to synthetic organic matter and accumulate dry matter, leading to reduced seed setting rate, grain mass, and seed weight [17-21]. A reduction in rainfall will decrease the stomatal conductance and intercellular $\mathrm{CO}_{2}$ flux, which will slow down the transpiration rate and restrict photosynthesis [22]. As a result, the uptake of nutrients will be reduced, and respiration consumption will increase oppositely. Therefore, the increase of precipitation in a moderate range can promote rice yield.

Based on the above analyses, we propose the following hypothesis:

Hypothesis 1 (H1). The increase of temperature and decrease of precipitation will restrain the rice yield.

\subsection{Indirect Effects of Climate Change on Rice Yield}

However, climatic factors not only serve as a direct driver of rice yield but also affect rice yield through their impact on the rice production factors such as labor, irrigation conditions, and chemical fertilizer application rates. Below we will further analyze in detail the indirect influence of climate change on rice yield.

\subsubsection{Irrigation Area}

The irrigation area, one of the most critical factors that affect agricultural output, is significantly influenced by the weather conditions. Considering that rice is a crop highly dependent on water resources, the increase of temperature and decrease of precipitation will enhance potential evaporation and reduce the availability of soil moisture, thus causing a greater need for agricultural irrigation during the rice reproductive stage [23]. Irrigation systems such as pumping stations, water conservancy facilities and so on will be scaled up to deal with water resource instability $[24,25]$. Although new agricultural technology, such as planting drought-tolerant varieties of rice, can be adopted to mitigate the drought, it will take much time for farmers to understand and master the technology without professional guidance. What is more, owing to the existence of information asymmetry and lack of knowledge about new technology, it will increase the transaction cost during the sales of new varieties of rice. As a result of that, the adaptive cost of using new technology will increase [26]. Besides, under the framework of the separation of three rights relating to Chinese agricultural land (rights to ownership, contracting, and management), the transfer of management right promotes farmland scale, which will reduce the construction and bargaining cost of irrigation facilities. As a consequence, the effective irrigation area is promoted $[27,28]$.

If sufficient irrigation water is guaranteed, the need for water during the rice-growing period will be ensured. The heat damage and water stress brought about by drought can be mitigated [29]. These investments in improving irrigation will positively affect rice production even during dry years $[30,31]$. Hence, the rice yield will get promoted. Based on the above analysis, we propose the following hypothesis:

Hypothesis 2 (H2). The decrease of precipitation and increase of temperature will stimulate the expansion of effective irrigation area, and thus actually lead to increased rice yield. 


\subsubsection{Fertilizer Application Amount}

The increasing temperature and decreasing precipitation will promote the decomposition and mineralization of soil organic matter, thus accelerating the loss of nutrients [32,33]. Meanwhile, drought will make microbiological living in soil suffer a degradation, which will restrain the nutrient circulation and lead to a decrease of microbial biomass carbon and nitrogen in soil [34,35]. What is more, the increase in temperature will aggravate soil erosion, and a high degree of evaporation will also cause soil salinization [36]. As a result of that, the soil fertility declines.

Reasonable use of chemical fertilizers plays a more significant role during the growth period of rice [37]. With the deterioration of soil conditions, the application of chemical fertilizers will be increased to promote the content of soil organic matter, total nitrogen, and alkali-hydrolyzed nitrogen [38]. However, excessive fertilizer application may also cause a decline in rice yield. In fact, under technical guidance, farmers will learn to command the appropriate amount of chemical fertilizers to be applied after sufficient trials and errors. Therefore, the phenomenon of soil infertility caused by climate change will be relieved after the increased and appropriate application of chemical fertilizers, providing ample nutrients to the growth of rice [39]. Based on this, we propose the following hypothesis:

Hypothesis 3 (H3). The decrease of precipitation and the increase of temperature will promote the application of chemical fertilizers to optimize soil fertility, thus increase rice yield.

\subsubsection{Labor Force}

The development of agriculture obviously cannot be separated from the support of the labor force. The increasing frequency and intensity of heatwaves caused by rising temperatures and less precipitation can lead to malnutrition, heat strain, and dehydration of farmers, thus decreasing their labor efficiency $[40,41]$. Furthermore, temperature and precipitation can also have an impact on the seasonal distribution and density of mosquitos, which will increase the risk of an epidemic of infectious diseases. Scholars also found that extreme weather is linked to a significant increase in mortality [42,43]. As a result of that, the quantity of labor supply has decreased.

Climate change, especially extreme weather events, will affect natural capital such as farmland and change household income [44,45]. Scholars found that the intensification of drought made it more difficult for Ethiopian herders to obtain water resources, leading to a transfer to the non-agricultural sector and reduction of the proportion of agricultural income. To cope with climate change, diversification of non-agricultural livelihood has been adopted by farmers [46,47]. As a result, the tendency of labor force migration from the agricultural sector to other industries is enhanced, leaving an increasing number of farmland uncultivated [48,49]. In sum, climate change may cause a decline in the supply of the agricultural labor force, leading to a decline in rice production. Based on this, we propose the following hypothesis:

Hypothesis 4 (H4). The decrease of precipitation and the increase in temperature lead to a reduced amount of labor supply, thus reducing rice yield.

Based on the analysis above, we summarize the influence mechanisms of climate change on rice yield in Figure 1: 


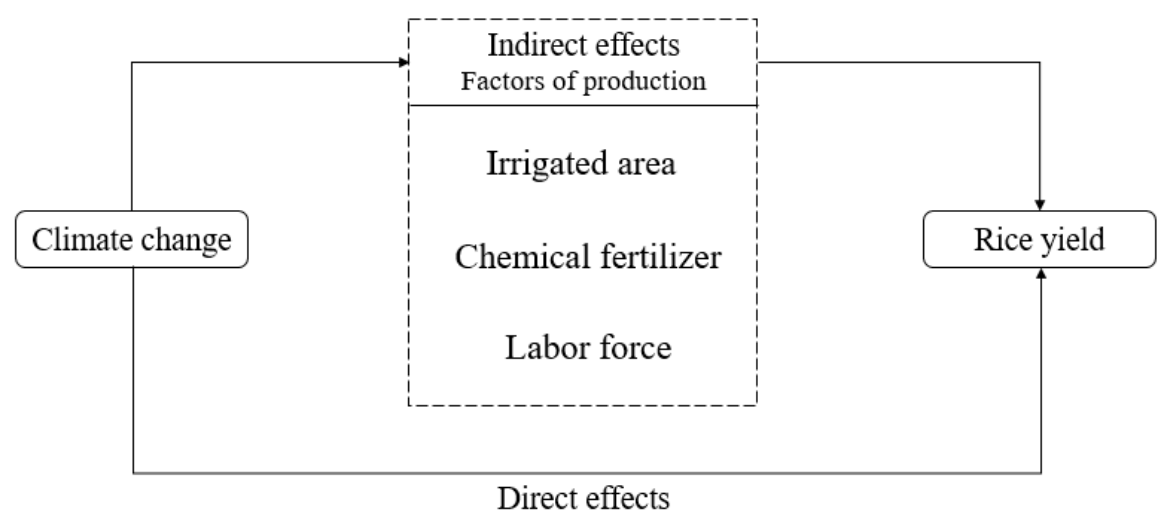

Figure 1. The hypothesized conceptual model. Source: Authors' depiction.

\section{Data and the Empirical Model}

\subsection{Study Area}

According to the National Bureau of Statistics of China (NBS), rice accounts for approximately 50 percent of the grain output and roughly 35 percent of the total grain consumption in China. Meanwhile, it can make a profound impact on the international grain market. The rice sector in China has experienced an impressive yield growth, and the average annual rate is nearly $15 \%$ during the period 1990-2016. Rice is widely cultivated in all provinces in China except for Qinghai. Due to the spatial differences in climatic and geographical conditions, rice-growing varies considerably across regions. As shown vividly in Figure 2, Rice is primarily produced in northeast provinces (Heilongjiang, Jilin, and Liaoning), Central China, East China, and some Southwest inland area (Sichuan and Yunnan). Meanwhile, the proportion of rice acreage in northeast provinces has increased at more than $10 \%$ during the past decades, making the region an essential rice-producing area in China. The proportions in Central China and Southwest inland area are stable, accounting for about $31 \%$ and $15 \%$, respectively. They play an essential role in ensuring national rice production safety. However, the proportion in the south and east China has suffered a decline during the past decades.

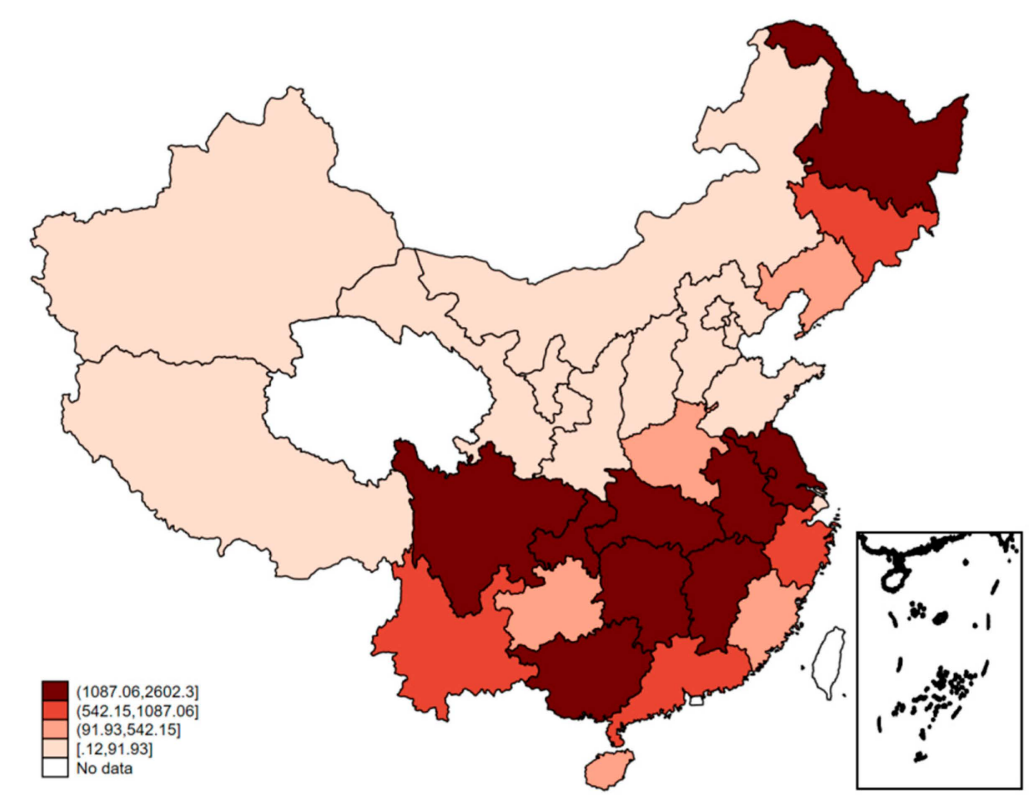

Figure 2. Distribution of rice production across China. 


\subsection{Variable Measurement}

\subsubsection{Dependent Variable: Rice Yield}

Rice tops China's three main grains, and its annual sown area is much higher than that of wheat and corn. In 2017, the sown area of rice had already exceeded the total sown area of wheat and corn by a difference of 33,857.57 thousand hectares, with the rice sown area accounting for about $70 \%$ of the total grain crop. Therefore, rice has an incomparable position among the whole grain development in China. In our empirical study, the rice yield (RICE) of China's provinces is selected from the "China Statistical Yearbook" (1991 to 2017) as the explained variable. The unit of rice yield is 10,000 tons.

\subsubsection{Explanatory Variables: Climate Change}

According to the above theoretical analysis, temperature and precipitation, two significant factors of climate conditions, mainly affect rice yield. Therefore, we select precipitation and temperature as the explanatory variables. To reflect gradual climate changes instead of weather shock and smooth out drastic year-to-year fluctuations, we refer to Cui [16] and use the average of weather in the preceding 30 years to form climate variables for each year. It should be emphasized that the temperature variable includes the average (Tave), minimum (Tmin), and maximum temperature (Tmax). Although other climatic factors, such as shallow temperature and too high temperature, also affect rice yield to a certain extent, these variables are not included in the panel data to avoid multicollinearity [16,20].

The raw data is obtained from the National Meteorological Data Center, which records daily meteorological data from 820 meteorological stations throughout the county, including daily minimum, maximum, and average temperatures and precipitation. We calculate the average climate indexes from each station in a given province to achieve the climate data at the provincial level.

\subsubsection{Intermediate Variables: Irrigated Area, Fertilizer Application Amount, and Labor Force}

According to the above theoretical analysis, the effective irrigated area (EIA), fertilizer application amount (FAA), and the labor force (LAB) are used as the intermediary variables in this paper. The EIA and FAA are from the Statistical Yearbook (in each calendar year), and their units are 1000 hectares and 10,000 tons, respectively. The total number of agricultural laborers cannot be obtained directly from the statistical yearbook, referring to the existing literature [50]. The proportion of the agricultural output value in the total output value of agriculture, forestry, animal husbandry, and sideline fishery is used as a measure of the proportion of total agricultural labor force in the total labor force of the broadly defined agriculture, forestry, animal husbandry, and fishery sector. Then the agricultural labor force is calculated by multiplying the total number of the rural labor force with the proportion we described above (In particular, the agricultural labor force $=$ agricultural, forestry, animal husbandry and sideline fishery employees $\times$ (agricultural output value/total agricultural, forestry, animal husbandry and sideline fishery output value)). The total output value of agriculture, forestry, animal husbandry, and fishery, and the total agricultural output value are mainly taken from the "China Compendium of Statistics 1949-2008" and the "(Regional years) Statistical Yearbook."

\subsubsection{Control Variables}

Referring to the relevant literature, we select the total power of agricultural machinery (TAM) [20], the rice planting area (RPA) [51], and the agricultural product price index (API) [52] as control variables to alleviate the problem of omitted variables. The TAM and RPA are mainly taken from the "China Statistical Yearbook" from 1990 to 2016. The API is from the "China Yearbook of Agricultural Price Survey."

Considering that Chongqing was separated from Sichuan Province into a separate municipality in 1997 when data was collated, Chongqing was merged into Sichuan for research. Since Qinghai Province is unable to grow rice due to its geographical location, there is no rice yield data for that 
province. Therefore, we conduct an empirical analysis on panel data of 30 provinces in China from year 1990 to 2016. Descriptive statistics of the variables are shown in Table 1.

Table 1. Summary statistics of variables.

\begin{tabular}{|c|c|c|c|c|c|c|}
\hline Variable & Description & Mean & $\begin{array}{l}\text { Std. } \\
\text { Dev. }\end{array}$ & Min & Max & Obs \\
\hline $\begin{array}{l}\text { Dependent } \\
\text { variable }\end{array}$ & Rice Yields (RICE) & 655.459 & 732.016 & 0.120 & 2644.81 & 783 \\
\hline \multirow{4}{*}{$\begin{array}{c}\text { Explanatory } \\
\text { variables }\end{array}$} & Rainfall (RAIN) & 8.952 & 0.648 & 6.883 & 10.087 & 783 \\
\hline & Average Temperature (Tave) $10^{\circ} \mathrm{C}$ & 1.333 & 0.545 & 0.138 & 2.537 & 783 \\
\hline & Highest Temperature (Tmax) $10^{\circ} \mathrm{C}$ & 1.888 & 0.467 & 0.831 & 2.973 & 783 \\
\hline & Lowest Temperature (Tmin) $10^{\circ} \mathrm{C}$ & 0.885 & 0.648 & -0.515 & 2.249 & 783 \\
\hline \multirow{3}{*}{$\begin{array}{l}\text { Intermediate } \\
\text { variables }\end{array}$} & Effective irrigation area (EIA) & 1909.267 & 1421.641 & 81.500 & 5932.740 & 783 \\
\hline & Fertilizer application amount (FAA) & 156.479 & 128.876 & 1.500 & 716.090 & 783 \\
\hline & Labor force (LAB) & 587.275 & 490.515 & 17.270 & 2678.890 & 783 \\
\hline
\end{tabular}

\subsection{Model Specification}

Since crop model that neglects socioeconomic factors tends to overestimate the effect of climate change on crops [53], this paper constructs econometric models to measure the direct effect and the indirect effect of climate change on rice yield, respectively, as illustrated in the hypothesized conceptual model.

\subsubsection{Testing the Direct Effect}

Considering that there may exist unobservable regional heterogeneity and time-varying but location-constant factors, we refer to the relevant literature to introduce a two-way fixed effect model as a benchmark regression to estimate the direct impact of climate change on rice yield $[20,54]$. The two-way fixed effect model can alleviate the interference of omitted variable bias on the estimation results by controlling both time-invariant provincial fixed effect and year fixed effect. At the same time, in order to solve the problems of heteroscedasticity and auto-correlation, we adopt the province-level clustering robust standard error $[20,55]$. In particular, we construct the following regression model:

$$
\operatorname{RICE}_{i t}=\beta_{0}+\beta_{x} X_{i t}+\sum_{j=0} \beta_{j} Z_{i t}+\gamma_{t}+\mu_{i}+\varepsilon_{i t},
$$

where RICE represents rice yield. $X$ are the key explanatory variables in the model, including precipitation and temperature normals. $Z$ is the control variables, $\gamma_{t}, \mu_{i}$, and $\varepsilon_{i t}$ are the individual effects that do not change with time, time effects that do not change with individuals, and the random error term that varies with time and with individuals, respectively. We mainly focus on the coefficient $\beta_{x}$. If it is significant, it indicates that the direct impact of climate change on rice yield does exist.

\subsubsection{Testing the Mediation Effect}

Referring to Edwards and Lambert [56], we construct a mediation effect model and use a causal steps approach to verify whether climate change affects the effective irrigation area (EIA), fertilizer application (FAA), and the agricultural labor force (LAB), and thus eventually influence rice yield. The regression models are as follows:

$$
\begin{gathered}
\text { mediation }_{i t}=\theta_{0}+\theta_{x} X_{i t}+\sum_{j=0} \theta_{j} Z_{i t}+\gamma_{t}+\mu_{i}+\varepsilon_{i t}, \\
\operatorname{RICE}_{i t}=\varphi_{0}+\varphi_{x} X_{i t}+\varphi_{m} \text { mediation }_{i t}+\sum_{j=0} \varphi_{j} Z_{i t}+\gamma_{t}+\mu_{i}+\varepsilon_{i t},
\end{gathered}
$$


where mediation $_{i t}$ represents the mediating variable, including the EIA, FAA, and LAB. $\mathrm{Z}$ is the control variables in the model, including the total power of agricultural machinery (TAM), the rice planting area (RPA), and the agricultural product price index (API).

The three regressions estimated through Equations (1)-(3) enable us to test the linkages of the mediation effect mode. Referring to the classical paper of Baron and Kenny [57], to establish mediation in our explored question, the following conditions need to hold: First, climate change must affect rice yield (Equation (1)), and in particular, the estimated coefficient $\beta_{x}$ needs to be statistically significant; second, climate change must affect the mediator (Equation (2)); and third, the mediator variable must affect rice yield while controlling for climate change (Equation (3)). In addition to that, if meanwhile, both estimated coefficients $\theta_{x}$ and $\varphi_{m}$ are statistically significant, it will indicate the existence of the mediating effect. Furthermore, if the coefficient $\varphi_{x}$ is not statistically significant, it will demonstrate a perfect mediational effect. However, if at least one of the coefficients $\theta_{x}$ and $\varphi_{m}$ is not significant, then we will need to examine the statistical significance of the null hypothesis: $\theta_{x} * \varphi_{m}=0$ using the Sobel test or the Bootstrap method. If $\theta_{x} * \varphi_{m}=0$ is significant, it will indicate the existence of the mediating effect. Moreover, under the background, that coefficient $\varphi_{x}$ is statistically significant, we should compare the symbol of $\theta_{x} * \varphi_{m}$ and $\varphi_{x}$. If the symbol is consistent, it indicate the presence of a partial mediation effect, otherwise indicating the presence of the cover effect.

\section{Results and Discussion}

\subsection{Direct Effect}

Table 2 presents the regression results on the direct impact of climate change on the rice yield. LS1, LS2, and LS3 show the impact of rainfall and the average temperature, maximum temperature, and minimum temperature, respectively, on rice yield. When controlling other potential or unobserved disturbing factors, it can be seen that regardless of whether Tave, Tmax, or Tmin is controlled, rainfall always has a positive effect on rice yield at a level of $p<1 \%$, and the estimated coefficient of the elasticity is 1.492, 1.580, and 1.532, respectively, in the three regressions (LS1, LS2, and LS3). Temperature, including the average, maximum, and minimum temperature, have a negative effect at the level of $p<10 \%$, and the coefficients of the semi-elasticity are $-0.787,-0.678$, and -0.710 , respectively, for the selected temperature variable (Tave, Tmax, and Tmin). In sum, our results show that the increase in temperature and decrease of precipitation significantly reduce rice yield, which means that climate change significantly affects the agricultural output in China. This is consistent with Chens' and Li's findings, and $\mathrm{H} 1$ is verified $[19,52,55]$.

According to Chen's findings, temperatures above $28{ }^{\circ} \mathrm{C}$ can cause massive reductions in rice yield by constraining the photosynthesis of rice and reducing pollen production $[5,19,55]$. The number of days with average temperatures above the threshold, $28^{\circ} \mathrm{C}$, tends to increase during the recent decade, according to China Meteorological Data. What is more, China has also witnessed a boost in the frequency of too high temperatures. In particular, the number of days with the highest temperature exceeding $33{ }^{\circ} \mathrm{C}$ has increased from 31.9 to 36.1 in the recent decade. Meanwhile, some provinces, which serve essential roles in the stability of Chinese rice yields such as Hunan and Jiangxi, have also witnessed a warming trend. Without a doubt, rising temperatures in the future will make heat damage more severe, which will significantly affect rice yield in major rice-producing regions of China.

There still exist arid and semi-arid regions, especially in northeast China, an essential rice producing area. Therefore, the increase of precipitation can ease the threat to rice yield posed by drought. 
Table 2. The regression results for the direct effect.

\begin{tabular}{cccc}
\hline & LS1 & LS2 & LS3 \\
\cline { 2 - 4 } & RICE & RICE & RICE \\
\hline \multirow{2}{*}{ RAIN } & $1.492^{* * *}$ & $1.580^{* * *}$ & $1.532^{* * *}$ \\
& $(0.297)$ & $(0.312)$ & $(0.316)$ \\
Tave & $-0.787^{*}$ & & \\
& $(0.435)$ & & \\
Tmax & & $-0.678^{*}$ & \\
& & $(0.388)$ & \\
Tmin & & & $-0.710^{*}$ \\
& & & $(0.409)$ \\
Constant & $-6.177^{*}$ & $-6.539 * *$ & $-7.000 *$ \\
Control & $(3.347)$ & $(3.162)$ & $(3.336)$ \\
YEAR & Yes & Yes & Yes \\
PROVINCE & Yes & Yes & Yes \\
$N$ & 783 & Yes & Yes \\
$R^{2}$ & 0.914 & 783 & 783 \\
\hline
\end{tabular}

Note: ${ }^{*}, * *$, and ${ }^{* * *}$ represent significance at $10 \%, 5 \%$ and $1 \%$ levels, respectively.

\subsection{Indirect Effects}

The above results show that climate change has a significant impact on the rice yield, prompting us to delve into the question of what the mechanism behind the effect of climate change on the rice yield is. In other words, what are the critical variables through which climate change influences rice yield? According to our theoretical analysis on the channel and influence mechanisms through which climate change affects rice yield in China, the effective irrigated area, the amount of fertilizers used, and the agricultural labor force, are selected as the mediating variables in our empirical investigation. Intermediate effect tests were carried out by using the stepwise method to take a further investigation of how climate change impacts the allocation of rice production factors and thus influencing the rice yield. Table 3 presents the regression results on the indirect impact of climate change on the rice yield.

Table 3. The regression results of the mediating effect of climate change.

\begin{tabular}{|c|c|c|c|c|c|c|}
\hline & LS4 & LS5 & LS6 & LS7 & LS8 & LS9 \\
\hline & $E I A$ & RICE & $F A A$ & RICE & $L A B$ & RICE \\
\hline RAIN & $\begin{array}{c}-0.636^{* * *} \\
(0.171)\end{array}$ & $\begin{array}{c}0.893^{* * *} \\
(0.246)\end{array}$ & $\begin{array}{c}-0.537^{* * *} \\
(0.177)\end{array}$ & $\begin{array}{c}0.294^{* * *} \\
(0.094)\end{array}$ & $\begin{array}{c}0.519^{* *} \\
(0.204)\end{array}$ & $\begin{array}{c}1.213^{* * *} \\
(0.226)\end{array}$ \\
\hline Tave & $\begin{array}{l}0.643 * \\
(0.331)\end{array}$ & $\begin{array}{c}2.351 * * * \\
(0.589)\end{array}$ & $\begin{array}{c}1.329 * * * \\
(0.394)\end{array}$ & $\begin{array}{c}1.684^{* * *} \\
(0.490)\end{array}$ & $\begin{array}{c}-1.240^{* * *} \\
(0.404)\end{array}$ & $\begin{array}{c}2.905 * * * \\
(0.368)\end{array}$ \\
\hline$E I A$ & & $\begin{array}{c}1.492^{* * *} \\
(0.285)\end{array}$ & & & & \\
\hline$F A A$ & & & & $\begin{array}{c}0.761^{* * *} \\
(0.202)\end{array}$ & & \\
\hline$L A B$ & & & & & & $\begin{array}{c}1.314 * * * \\
(0.314)\end{array}$ \\
\hline Constant & $\begin{array}{c}6.816^{* * *} \\
(1.452)\end{array}$ & $\begin{array}{c}-17.707^{* * *} \\
(2.543)\end{array}$ & $\begin{array}{c}0.718 \\
(1.526)\end{array}$ & $\begin{array}{c}-8.108^{* * *} \\
(2.121)\end{array}$ & $\begin{array}{c}1.070 \\
(1.585)\end{array}$ & $\begin{array}{c}-22.041^{* * * *} \\
(2.024)\end{array}$ \\
\hline Control & Yes & Yes & Yes & Yes & Yes & Yes \\
\hline YEAR & Yes & Yes & Yes & Yes & Yes & Yes \\
\hline PROVINCE & Yes & Yes & Yes & Yes & Yes & Yes \\
\hline$N$ & 783 & 783 & 783 & 783 & 783 & 783 \\
\hline$R 2$ & 0.945 & 0.959 & 0.946 & 0.967 & 0.959 & 0.932 \\
\hline
\end{tabular}

Note: ${ }^{*}, * *$ and ${ }^{* * *}$ represent significance at $10 \%, 5 \%$ and $1 \%$ levels, respectively. 


\subsubsection{The Indirect Effect of Effective Irrigation Area on Rice Yield}

LS4 and LS5 present the regression results of the effective irrigation area (EIA) on rice yield. As outlined in Section 3.2.2, we first regress the mediator, EIA, on the climate change variables. We regress our ultimate explained variable, rice yield, on climate change, and the mediating variables. In LS4, we report the regression results of the impact of climate change on EIA. It shows that when Tave is controlled, RAIN has a significant negative effect on EIA. Meanwhile, Tave has a significant positive effect on EIA. These results indicate that the decrease of precipitation and increase of temperature leads to an expansion of the effective irrigation area in rice farming. In LS5, we then continue to report the regression results of the combined impact of climate change and mediating variables on the rice yield. It shows under the condition that climate change has a significant impact on the rice yield, the coefficients of EIA is significantly positive at the $1 \%$ level, which confirms the existence of the mediational effect of the effective irrigation area. On the other hand, one may also notice that in the multiple regressions LS4 through LS5, the impact of temperature on rice yield is still significant. However, the direction of its impact changes vis-à-vis its direct effect on rice yield reported in regressions LS1 through LS3. This seems to strengthen our argument that temperature may not have primarily affected rice yield directly, but mainly through its impact on certain mediating factors such as EIA, which directly influences rice yield. The indirect (positive) effect of temperature dominates its direct (negative) effect on rice yield; thus, in the regressions that are inclusive of the mediating variable, the coefficients of the temperature variable become positive. One more point to note is that in regressions LS5 that include the mediator, the estimated coefficients of RAIN and temperature variables remain statistically significant, indicating that the identified mediational effect is not a perfect one.

Model results show that under the control of precipitation, annual average temperature, and other control variables, the effective irrigation area increased by $1 \%$, and the rice yield increased by $1.492 \%$ on average. A decrease in precipitation and an increase in temperature can cause a shortage of agricultural water resources, threatening the rice yield. However, drought will also motivate farmers to take active measures such as adopting improved irrigation methods or increasing irrigation frequency to resist and mitigate the adverse effects of drought events on rice yield per unit area. As a result of that, the effective irrigation area will be expanded, and the needs of water during rice growth can be guaranteed, which will promote rice yield. Heat damage and drought caused by direct climate change on rice yield will also be partially mitigated. The results are consistent with those of Rüdiger and colleagues [58], and our hypothesis $\mathrm{H} 2$ has been verified.

Some scholars further pointed out that the increase of effective irrigation area plays a vital role in rice yield in China, especially in the northwest of China and North China plain, where severe drought events frequently occur [27]. Hence, the mediating effect of effective irrigation area may have well partially accounted for China's positive outcomes of rice yield even under the increasingly adverse precipitation conditions. What is more, an effective irrigation area is inseparable from the well-constructed farmland water conservancy infrastructure. So, investment should be paid to farmland water conservancy facilities to improve the reliability of irrigation water supply to motivate farmers to adopt adaptive behavior. For a long time, China has been paying close attention to the importance of strengthening water resource and irrigation management infrastructure. According to the China Statistical Yearbook, China's effective irrigation area has been significantly increased from 47,403.10 thousand hectares in 1990 to 67,140.62 thousand hectares in 2016.

\subsubsection{The Indirect Effect of Chemical Fertilizer Applications on Rice Yield}

In LS6 and LS7, we present the regression results of the mediating effect of chemical fertilizer applications (FAA) on rice yield. Referring to what is typically done in estimating mediational effect, we first regress the FAA on climate change (regressions LS6), followed by regressing rice yield on both climate change and FAA (regressions LS7). In LS6, it shows that when Tave is controlled, RAIN has a significant adverse effect on the FAA. Meanwhile, Tave has a positive effect on the FAA at the level of $p<1 \%$, which indicates that the decrease of precipitation and increase of temperature will 
stimulate chemical fertilizer applications. Regressions LS7 shows that under the condition that climate change has a significant impact on the rice yield, the coefficient of FAA is significantly positive at the $1 \%$ level. This result will not only confirms the existence of the mediating effect of chemical fertilizer applications but also explains that the decrease of precipitation and increase of temperature seem to have motivated farmers to make more use of chemical fertilizer applications optimally. This will help to improve soil fertility and ensure nutrition during the growth period of rice. Moreover, similarly, as observed and discussed in the immediately preceding section, after controlling for the mediator variable, FAA, in the regressions, the effect of RAIN on RICE remains statistically significant. However, it becomes smaller compared with its direct effect. Again, the fact that the coefficients for RAIN and temperature estimated in regressions LS6 through LS7 are still statistically significant implies that the mediational effect of FAA, albeit strong, is not a perfect one.

Model results show that under the control of precipitation annual average temperature and other control variables, the chemical fertilizer application increased by $1 \%$, and the rice yield increased by $0.761 \%$ on average. Arid and hyperthermal soil caused by climate change will restrain the nutrient circulation and then pose a threat to sufficient nutrients during the rice growth period. However, farmers will have incentives to apply a higher amount of chemical fertilizers to improve soil fertility. As a result of that, soil fertility will improve, and the nutrient needed by rice growth can be ensured. Hence, the rice yield will be promoted. This has also been verified in existing literature [59], and our hypothesis $\mathrm{H} 3$ is verified.

An increasing amount of fertilizer application can improve soil fertility and mitigate the adverse direct effect from climate change, especially in the Northeast and North China plain, where the tendency of warming and drought has significantly caused decomposition and mineralization of soil organic matter and accelerated the nutrient loss. Hence, the mediating effect of fertilizer application may have well partially accounted for China's positive outcomes of rice yield even under the increasingly adverse drought and warming conditions. According to China Statistical Yearbook, fertilizer applications increased from 25.903 million tons in 1990 to 5984.41 million tons in 2016. Therefore, though climate change creates a negative shock to the rice yield, increased fertilizer applications in response to climate change may have offset the impact and led to growing rice yield. While scholars also point out that although the increase of chemical fertilizer amount can promote rice yield in the short run, the excessive use of $\mathrm{N}$ fertilizer will accelerate global warm tendency through $\mathrm{N} 2 \mathrm{O}$ emission. That will constrain the effects on the use efficiency of fertilizer during the growth of rice, thus negatively affecting rice yield $[60,61]$. So, the increase of fertilizer application amount may be useful in the short run, but we need to adopt more advanced fertilization management to ensure sustainable rice yield growth.

\subsubsection{The Indirect Effect of the Agricultural Labor Force on Rice Yield}

In LS8 and LS9, we report the regression results of the mediating effect of the agricultural labor force (LAB) on rice yield. Regressions of LAB on climate change variables in LS8 shows that when Tave is controlled, RAIN has a significant positive effect on LAB at the level of $p<5 \%$. Meanwhile, Tave has a negative impact on $\mathrm{LAB}$ at the level of $p<1 \%$, indicating that the increase of precipitation promotes labor productivity while the increase of temperature has a significant and opposite effect. Regressions of rice yield on both climate change variables and LAB in LS9 show that under the condition that climate change has a significant impact on the rice yield, the coefficient of LAB is significantly positive at the $1 \%$ level. This result not only confirms the existence of the mediating effect of the agricultural labor force but also explains that the decrease of precipitation or increase of temperature lowers labor productivity during the growth of rice. The fact that the climate change variables retain a significant effect on RICE after controlling for the mediator variable (LAB) in the regressions implies a partial, not a perfect mediational effect of LAB.

Model results show that under the control of precipitation annual average temperature and other control variables, the labor force decreased by 1 unit, and the rice yield decreased by 1.314 on average. Climate change will enhance migration from the agricultural sector to other industries and reduce the 
quantity of labor force directly. As a result of that, the labor force during the growth of rice will be reduced, and the rice yield will suffer a decrease. This has also been verified in existing literature [62], and our hypothesis $\mathrm{H} 4$ is verified.

With the loosening relationship between farmers and farmland, China is transforming from rural China to rural-urban China. Farmers, especially the second generation, have shown the tendency of staying in the city for work and leaving agriculture [49]. Climate change will enhance the non-agricultural transfer by affecting natural capital, such as farmland, to increase the risk and vulnerability of farmers' livelihood [44]. The off-farm transfer of rural labor force, mostly young and middle-aged labor force, will not only shrink the scale of high-quality labor force input in rice planting but also reduce farmland management efficiency and increase the possibility of farmland being abandoned. The off-farm transfer of the young and middle-aged labor force will also lead to the aging and feminization of the rural labor force structure, reducing the proportion of rice planted. To mitigate the negative indirect effect of a shrinking labor force caused by climate change, it is necessary to strengthen the substitution of mechanized and large-scale operation for the labor force in rice yield.

From both the analysis of direct and indirect effects that climate change has caused on rice yield, one can find that we need to evaluate the impact of climate change on rice yield in an integrative way, not just focusing on the direct effect. Although the increase of temperature and decrease of precipitation will directly restrain the accumulation of matter and cut down the seeding rate during the growth period of rice, climate change motivates farmers to respond positively by investing in and promoting adaptive production technologies; thus, at least in the short run the adversely evolving weather conditions lead to improved total factor efficiency of rice yield. In the short run, the positive indirect effect can outweigh the adverse direct effect, vividly demonstrating the juxtaposed risks and opportunities presented by climate change for agricultural development. For instance, when facing the risk of unstable water resources, farmers will drill wells, build reservoirs, maintain canals, and buy pumps to expand effective irrigation areas. As a result, the quantity and efficiency of water resources allocated to rice production have been promoted.

Similarly, upon the risk of low soil fertility, farmers increase chemical fertilizer intensity, improve measures of fertilization to increase the practical application of chemical fertilizers. In other words, the total production factors allocated to rice farming are promoted in response to climate change, which can compensate for the negative impact the climate may have on rice yield. Therefore, we should combine the direct effect with the indirect effect to comprehensively evaluate the integrated influence of climate change on rice yield.

\section{Conclusions and Policy Recommendations}

Using China's data of weather conditions and agricultural output, we empirically identify the mediational effect of various production factors in response to climate change on the rice yield. First, we find that climate change leads to expanded effective irrigation areas through farmers' and government's investments in improving the irrigation system and efforts, which can more than offset the adverse effect of decreased precipitation and increased temperature on China's rice output. Second, though abnormal weather can lead to poor soil fertility, farmers' response to increased use of chemical fertilizers may offset the negative impact of the worsened soil fertility on rice production. Third, climate change, especially the rising temperature, can lead to a shortage of agricultural labor, thus adversely affect the rice yield. In summary, the indirect effect of climate change on rice yield cannot be underestimated.

To improve China's rice yield and ensure the safety of rice supply, several preliminary policy suggestions in the context of challenges that climate change poses on agricultural development might be drawn upon our analyses. First, it is necessary to strengthen farmers' awareness of water conservation and make full use of treated industrial sewage water that can be used for agricultural irrigation purposes to make up for the shortage of irrigation water. Furthermore, strengthening investments in infrastructure such as irrigation channels and improving irrigation technology to reduce unnecessary waste of irrigation water is nearly essential. Second, to maintain and improve soil fertility in a balanced 
way, the government and relevant trade associations should regularly hold special workshops and provide effective communication and guidance to farmers on the rational use of chemical fertilizers in rice farming. Third, the government should promulgate policies to support and ensure sufficient agricultural labor supply, particularly challenging in an era of industrialization and urbanization that causes continuous labor migration out of the agricultural sector. Improving the agricultural product market mechanism may lead to improved farming profits, attracting more labor force to stay in or enter rice farming. Investing in agricultural technological innovations, on the other hand, may increase labor productivity and reduce the need for labor quantity. Also, the government should take effective post-disaster measures to alleviate labor loss following the negative shock of catastrophe weather.

Other climatic factors, such as solar radiation and humidity, can also affect rice yield [52,63]. Furthermore, owing to the limitation of data available, we only focused on expanding the effective irrigation area and increasing the fertilizer amount. Farmers have adopted more comprehensive and efficient water and fertility management strategies and other adaptive behavior under changing climate [61,64]. Therefore, further research can not only take more climate factors into account in the model but also incorporate quantitative indicators of other indirect effects into the empirical model to enrich and improve the analysis of the indirect effect of climate change on rice yield.

Author Contributions: Data curation, Y.L.; formal analysis, W.H.; methodology, W.H.; software, Y.L.; supervision, W.H.; validation, H.S. and F.T.-H.; writing-original draft, Y.L. and W.H.; writing-review and editing, W.H. and F.T.-H. All authors have read and agreed to the published version of the manuscript.

Funding: This research was funded by (National Natural Science Foundation of China) grant number (72003097, 71774071), (Humanities and Social Sciences Research of Ministry of Education of China) grant number (18YJC790041), (Natural Science Foundation of Jiangsu Province) grant number (BK20190775), (Natural Science Foundation of Jiangsu Higher Education Institutions of China) grant number (18KJB220009), (Japan Society for the Promotion of Science (JSPS) Kakenhi (2019-2020) Grant-in-Aid for Young Scientists) grant number (19K13742).

Acknowledgments: Wenjian He is grateful for the financial support provided by the National Natural Science Foundation of China (72003097, 71774071), the Humanities and Social Sciences Research of Ministry of Education of China (18YJC790041), the Natural Science Foundation of Jiangsu Province (BK20190775), and the Natural Science Foundation of Jiangsu Higher Education Institutions of China (18KJB220009). Farhad Taghizadeh-Hesary acknowledges the financial supports of the Japan Society for the Promotion of Science (JSPS) Kakenhi (2019-2020) Grant-in-Aid for Young Scientists No. 19K13742 and Grant-in-Aid for Excellent Young Researcher of the Ministry of Education of Japan (MEXT).

Conflicts of Interest: The authors declared that they have no conflict of interest to this work.

\section{References}

1. Watts, N.; Scales, I.R. Seeds, agricultural systems and socio-natures: Towards an actor-network theory informed political ecology of agriculture. Geogr. Compass 2015, 9, 225-236. [CrossRef]

2. Williams, S.; Hobday, A.; Falconi, L.; Hero, J.; Holbrook, N.; Capon, S.; Bond, N.; Ling, S.; Hughes, L. Research priorities for natural ecosystems in a changing global climate. Glob. Chang. Biol. 2020, 26, 410-416. [CrossRef]

3. Liu, J.; Stewart, R.E.; Szeto, K.K. Moisture transport and other hydrometeorological features associated with the severe 2000/01 drought over the western and central Canadian prairies. J. Clim. 2004, 17, 305-319. [CrossRef]

4. Wang, J.; Huang, J.; Yang, J. Overview of Impacts of Climate Change and Adaptation in China's Agriculture. J. Integr. Agric. 2014, 13,1-17. [CrossRef]

5. Wei, T.; Cherry, T.L.; Glomrod, S.; Zhang, T. Climate change impacts on crop yield: Evidence from China. Sci. Total Environ. 2014, 499, 133-140. [CrossRef]

6. Zhang, Z.; Chen, Y.; Wang, C.; Wang, P.; Tao, F. Future extreme temperature and its impact on rice yield in China. Int. J. Clim. 2017, 37, 4814-4827. [CrossRef]

7. Krishnan, P.; Swain, D.K.; Chandra Bhaskar, B.; Nayak, S.K.; Dash, R.N. Impact of elevated $\mathrm{CO}_{2}$ and temperature on rice yield and methods of adaptation as evaluated by crop simulation studies. Agric. Ecosyst. Environ. 2007, 122, 233-242. [CrossRef]

8. Lin, E.; Xiong, W.; Ju, H.; Xu, Y.; Xie, L. Climate change impacts on crop yield and quality with CO2 fertilization in China. Philos. Trans. Biol. Sci. 2005, 360, 2149-2154. [CrossRef] 
9. Yang, J.; Xiong, W.; Yang, X.; Cao, Y.; Feng, L. Geographic variation of rice yield response to past climate change in china. J. Integr. Agric. 2014, 13, 1586-1598. [CrossRef]

10. Christopher, R.B.; Barry, S.; Michael, B.; Thomas, R.J.; John, S.; Quentin, C.; Bhawan, S. Adaptation in Canadian agriculture to climatic variability and change. Clim. Chang. 2000, 45, 181-201. [CrossRef]

11. Howden, S.M.; Soussana, O.; Tubiello, F.N.; Chhetri, N.; Dunlop, M.; Meinke, H. Adapting agriculture to climate change. Proc. Nat. Acad. Sci. USA 2007, 104, 19691-19696. [CrossRef] [PubMed]

12. Liu, Y.; Wang, E.; Yang, X.; Wang, J. Contributions of climatic and crop varietal changes to crop production in the North China Plain, since 1980s. Global Chang. Biol. 2010, 16, 2287-2299. [CrossRef]

13. Welch, J.R.; Vincent, J.R.; Auffhammer, M.; Moya, P.F.; Dobermann, A.; Dawe, D. Rice yields in tropical/subtropical Asia exhibit large but opposing sensitivities to minimum and maximum temperatures. Proc. Nat. Acad. Sci. USA 2010, 107, 14562-14567. [CrossRef] [PubMed]

14. Schlenker, W. Crop responses to climate and weather: Cross-section and panel models. Clim. Chang. Food Secur. 2010, 37, 99-108. [CrossRef]

15. Field, C.; Lobell, D.; Peters, H.; Chiariello, N. Feedbacks of terrestrial ecosystems to climate change. Annu. Rev. Environ. Resour. 2007, 32, 1-29. [CrossRef]

16. Cui, X. Climate change and adaptation in agriculture: Evidence from US cropping patterns. J. Environ. Econ. Manag. 2020, 101, 102306. [CrossRef]

17. Wassmann, R.; Jagadish, S.V.K.; Heuer, S.; Ismail, A.; Redona, E.; Serraj, R.; Singh, R.K.; Howell, G.; Pathak, H.; Sumfleth, K. Climate change affecting rice production: The physiological and agronomic basis for possible adaptation strategies. Adv. Agron. 2009, 101, 59-122.

18. Bai, H.; Tao, F.; Xiao, D.; Liu, F.; Zhang, H. Attribution of yield change for rice wheat rotation system in China to climate change, cultivars and agronomic management in the past three decades. Clim. Chang. 2016, 135, 539-553. [CrossRef]

19. Chen, X.; Chen, S. China feels the heat: Negative impacts of high temperatures on China's rice sector. Aust. J. Agric. Resour. Econ. 2018, 62, 576-588. [CrossRef]

20. Chen, S.; Chen, X.; Xu, J. Impacts of climate change on agriculture: Evidence from China. J. Environ. Econ. Manag. 2016, 76, 105-124. [CrossRef]

21. Zafar, S.A.; Hameed, A.; Nawaz, M.A.; Wei, M.A.; Noor, M.A.; Hussain, M. Mechanisms and molecular approaches for heat tolerance in rice under climate change scenario. J. Integr. Agric. 2018, 17, 726-738. [CrossRef]

22. Brian, R.M.; Peter, B.A. Effects of precipitation on photosynthesis and water potential in Andropogon gerardii and Schizachyrium scoparium in a southern mixed grass prairie. Environ. Exp. Bot. 2011, 72, 223-231. [CrossRef]

23. Ju, H.; van der Velde, M.; Lin, E.; Xiong, W.; Li, Y. The impacts of climate change on agricultural production systems in China. Clim. Chang. 2013, 120, 313-324. [CrossRef]

24. Korres, N.E.; Norsworthy, J.K.; Burgos, N.R.; Oosterhuis, D.M. Temperature and drought impacts on rice production: An agronomic perspective regarding short- and long-term adaptation measures. Water Resour. Rural Dev. 2017, 9, 12-27. [CrossRef]

25. Stefan, S.; Heidi, W.; Zhao, G.; Frank, E. Heat stress is overestimated in climate impact studies for irrigated agriculture. Environ. Res. Lett. 2017, 12, 054023. [CrossRef]

26. Chen, M.; Sun, F.; Berry, P.; Tinch, R.; Ju, H.; Lin, E. Integrated assessment of China's adaptive capacity to climate change with a capital approach. Climatic Change 2015, 128, 367-380. [CrossRef]

27. Tan, S.; Heerink, N.; Qu, F. Land fragmentation and its driving forces in China. Land Use Policy 2006, 23, 272-285. [CrossRef]

28. Gao, L.; Huang, J.; Rozelle, S. Rental markets for cultivated land and agricultural investments in China. Agric. Econ. 2012, 43, 391-403. [CrossRef]

29. Masashi, O.; Toshichika, I.; Gen, S.; Naota, H. Modeling irrigation-based climate change adaptation in agriculture: Model development and evaluation in Northeast China. J. Adv. Model. Earth Syst. 2015, 7, 1409-1424. [CrossRef]

30. Stephen, N.N.; Hubert, H.G.S.; Josephine, N.T.; Johan, R.; Penning de Vries, F.W.T. Agro-hydrological evaluation of on-farm rainwater storage systems for supplemental irrigation in Laikipia district, Kenya. Agric. Water Manag. 2004, 73, 21-41. [CrossRef] 
31. Moseley, W.G. Agriculture on the brink: Climate change, labor and smallholder farming in Botswana. Land 2016, 5, 21. [CrossRef]

32. Sala, O.; Chapin, F.; Armesto, J.; Berlow, E.; Bloomfield, J.; Dirzo, R.; Huber-Sanwald, E.; Huenneke, L.; Jackson, R.; Kinzig, A.; et al. Global biodiversity scenarios for the year 2100. Science 2000, 287, 1770-1774. [CrossRef] [PubMed]

33. Eric, A.D.; Ivan, A.J. Temperature sensitivity of soil carbon decomposition and feedbacks to climate change. Nat. Int. Wkly. J. Sci. 2006, 440 (Suppl. 1), 165-173. [CrossRef]

34. Timo, D.; Leena, F.; Tarja, L.; Aino, S. Effect of soil temperature on nutrient allocation and mycorrhizas in Scots pine seedlings. Plant. Soil 2002, 239, 173-185. [CrossRef]

35. Rosacker, L.L.; Kieft, T.L. Biomass and adenylate energy charge of a grassland soil during drying. Pergamon 1990, 22, 1121-1127. [CrossRef]

36. Barrios, S.; Ouattara, B.; Strobl, E. The impact of climatic change on agricultural production: Is it different for Africa? Food Policy 2008, 33, 287-298. [CrossRef]

37. Mark, M. Pitt. Farm-level fertilizer demand in Java: A meta-production function approach. Am. J. Agric. Econ. 1983, 65, 502-508. [CrossRef]

38. Tomar, O.S.; Dagar, J.C.; Minhas, P.S. Evaluation of sowing methods, irrigation schedules, chemical fertilizer doses and varieties of Plantago ovata forsk to rehabilitate degraded calcareous lands irrigated with saline water in dry regions of northwestern India. Arid Soil Res. Rehabil. 2010, 24, 133-151. [CrossRef]

39. Zare, M.; Samani, A.A.N.; Mohammady, M.; Teimurian, T.; Bazrafshan, J. Simulation of soil erosion under the influence of climate change scenarios. Environ. Earth Sci. 2016, 75, 1405. [CrossRef]

40. Li, X.; Chow, K.; Zhu, Y.; Lin, Y. Evaluating the impacts of high-temperature outdoor working environments on construction labor productivity in China: A case study of rebar workers. Build. Environ. 2016, 95, 42-52. [CrossRef]

41. Tomoko, H.; Shinichiro, F.; Kiyoshi, T.; Tokuta, Y.; Toshihiko, M. Economic implications of climate change impacts on human health through undernourishment. Clim. Chang. 2016, 136, 189-202. [CrossRef]

42. Vaidyanathan, A.; Kegler, S.R.; Saha, S.S.; Mulholland, J.A. A statistical framework to evaluate extreme weather definitions from a health perspective a demonstration based on extreme heat events. Bull. Am. Meteorol. Soc. 2016, 97, 1817-1830. [CrossRef] [PubMed]

43. Limaye, V.S.; Vargo, J.; Harkey, M.; Holloway, T.; Patz, J.A. Climate change and heat-related excess mortality in the eastern USA. Ecohealth 2018, 15, 485-496. [CrossRef] [PubMed]

44. Gentle, P.; Narayan, T.M. Climate change, poverty and livelihoods: Adaptation practices by rural mountain communities in Nepal. Environ. Sci. Policy 2012, 21, 24-34. [CrossRef]

45. Kirchberger, M. Natural disasters and labor markets. J. Dev. Econ. 2017, 125, 40-58. [CrossRef]

46. Chavas, J.P.; Di, F.S. On the role of risk versus economies of scope in farm diversification with an application to Ethiopian farms. J. Agric. Econ. 2012, 63, 25-55. [CrossRef]

47. David, W.; Habtamu, Y.A.; Johannes, S. Social capital, income diversification and climate change adaptation: Panel data evidence from rural Ethiopia. J. Agric. Econ. 2018, 69, 458-475. [CrossRef]

48. Johanna, H.; Jenny, S.; Madelene, O.; Chen, D.; Yun, X.; Per, K. Climate variability and land-use change in Danangou Watershed, China-examples of small-scale farmers' adaptation. Clim. Chang. 2005, 7, $189-212$. [CrossRef]

49. Zhao, L.; Liu, S.; Zhang, W. New trends in internal migration in China: Profiles of the new-generation migrants. China World Econ. 2018, 1, 18-41. [CrossRef]

50. Li, N.; He, W.; Qiu, T.; Chen, L. Farmland property right structure, factor efficiency and agricultural performance. Manag. World 2017, 3, 44-62.

51. Cohn, A.S.; VanWey, L.K.; Spera, S.A.; Mustard, J.F. Cropping frequency and area response to climate variability can exceed yield response. Nat. Clim. Chang. 2016, 6, 601-604. [CrossRef]

52. Li, F.; Zhou, M.; Shao, J.; Chen, Z.; Wei, X.; Yang, J. Maize, wheat and rice production potential changes in China under the background of climate change. Agric. Syst. 2020, 182, 102853. [CrossRef]

53. Lobell, D.; Bänziger, M.; Magorokosho, C.; Vivek, B. Nonlinear heat effects on African maize as evidenced by historical yield trials. Nat. Clim. Chang. 2011, 1, 42-45. [CrossRef]

54. Elodie, B.; Wolfram, S. The use of panel models in assessments of climate impacts on agriculture. Rev. Environ. Econ. Policy 2017, 11, 258-279. [CrossRef] 
55. Chen, S.; Chen, X.; Xu, J. Assessing the impacts of temperature variations on rice yield in China. Clim. Chang. 2016, 138, 191-205. [CrossRef]

56. Edwards, J.R.; Lambert, L.S. Methods for integrating moderation and mediation: A general analytical framework using moderated path analysis. Psychol. Methods 2007, 12, 1-22. [CrossRef]

57. Baron, R.M.; Kenny, D.A. The moderator-mediator variable distinction in social psychological research: Conceptual, strategic, and statistical consideration. J. Personal. Soc. Psychol. 1986, 51, 1173-1182. [CrossRef]

58. Rüdiger, S.; Jennifer, K.; Tim, A.B.; Ellen, K.; Martina, F. Current and future irrigation water requirements in pan-Europe: An integrated analysis of socio-economic and climate scenarios. Glob. Planet. Chang. 2012, 94-95. [CrossRef]

59. Piao, S.; Ciais, P.; Huang, Y.; Shen, Z.; Peng, S.; Li, J.; Zhou, L.; Liu, H.; Ma, Y.; Ding, Y.; et al. The impacts of climate change on water resources and agriculture in China. Nature 2010, 467, 43-51. [CrossRef]

60. Tian, H.; Lu, C.; Jerry, M.; Ren, W.; Huang, Y.; Xu, X.; Liu, M.; Zhang, C.; Chen, G.; Pan, S.; et al. Food benefit and climate warming potential of nitrogen fertilizer uses in China. Environ. Res. Lett. 2012, 7, 044020. [CrossRef]

61. Yang, T.; Zeng, Y.; Sun, Y.; Zhang, J.; Tan, X.; Zeng, Y.; Huang, S.; Pan, X. Experimental warming reduces fertilizer nitrogen use efficiency in a double rice cropping system. Plant Soil Environ. 2019, 65, 483-489. [CrossRef]

62. Kniveton, D.R.; Smith, C.D.; Black, R. Emerging migration flows in a changing climate in dryland Africa. Nat. Clim. Chang. 2012, 2, 444-447. [CrossRef]

63. Xu, C.; Wu, W.; Ge, Q. Impact assessment of climate change on rice yields using the ORYZA model in the Sichuan Basin, China. Int. J. Climatol. 2018, 38, 2922-2939. [CrossRef]

64. Okada, M.; Iizumi, T.; Sakamoto, T.; Kotoku, M.; Sakurai, G.; Hijioka, Y.; Nishimori, M. Varying benefits of irrigation expansion for crop production under a changing climate and competitive water use among crops. Earths Future Int. J. Climatol. 2018, 6, 1207-1220. [CrossRef]

(C) 2020 by the authors. Licensee MDPI, Basel, Switzerland. This article is an open access article distributed under the terms and conditions of the Creative Commons Attribution (CC BY) license (http://creativecommons.org/licenses/by/4.0/). 